\title{
Neck circumference is associated with carotid intimal-media thickness but not with coronary artery calcium: Results from The ELSA-Brasil
}

\author{
C.P. Baena ${ }^{\mathrm{a}, \mathrm{b}}$, P.A. Lotufo ${ }^{\mathrm{a}, \mathrm{c}}$, I.S. Santos ${ }^{\mathrm{a}, \mathrm{c}}$, A.C. Goulart ${ }^{\mathrm{a}}$, M.S. Bittencourt ${ }^{\mathrm{a}}$, \\ B.B. Duncan ${ }^{\text {d }}$, S. Liu ${ }^{\text {e }}$, I.M. Benseñor ${ }^{\text {a,c,* }}$ \\ ${ }^{a}$ Center for Clinical and Epidemiologic Research, Hospital Universitario, São Paulo, Brazil \\ ${ }^{b}$ School of Medicine, Pontificia Universidade Católica do Paraná, Curitiba, Brazil \\ ${ }^{c}$ School of Medicine, University of São Paulo, São Paulo, Brazil \\ ${ }^{d}$ Postgraduate Studies Program in Epidemiology, School of Medicine, Federal University of Rio Grande do Sul, Porto Alegre, Brazil \\ ${ }^{e}$ School of Public Health, Brown University, Providence, RD, USA
}

Received 5 October 2015; received in revised form 8 January 2016; accepted 11 January 2016

Available online 22 January 2016

\section{KEYWORDS \\ Neck; \\ Carotid artery \\ diseases; \\ Body fat distribution}

\begin{abstract}
Background and aims: It is uncertain whether neck circumference can be a risk indicator for subclinical atherosclerosis. We aimed to investigate their relationships measured by coronary artery calcium (CAC) and common carotid intima-media thickness (cc-IMT) with neck circumference in ELSA-Brasil.

Methods and results: In cross-sectional and sex-specific analyses of 2266 women (50.6 $\pm 8.4 \mathrm{yrs}$ ) and 1886 men ( $50.7 \pm 9.0 \mathrm{yrs})$ with both cc-IMT and CAC, free from previous cardiovascular disease at baseline, we built logistic models using diverse cut-off points for CAC score ( $0 \mathrm{vs}>0,<100$ vs $\geq 100,<400$ vs $\geq 400$ Agatston units) and cc-IMT ( $<75$ th percentile vs $\geq 75$ th; $<90$ th percentile vs $\geq 90$ th) as dependent variables, after which adjustments for age and traditional cardiovascular risk factors were made. Mean neck circumference was $33.6( \pm 2.4 \mathrm{~cm})$ for women and 38.8 $( \pm 2.6 \mathrm{~cm})$ for men. In fully adjusted models including sociodemographic, cardiovascular risk factors and body-mass index and waist circumference, for each 1 standard deviation increase in neck circumference we found an odds ratio (OR, 95\% CI) for IMT above the 75th percentile of $(1.52,1.16 ; 1.99)$ for women and $(1.66,1.28 ; 2.14)$ for men, and above the 90th cc-IMT percentile [1.66 $(1.19 ; 2.32)$ for men but not for women $[1.21(0.80 ; 1.82)]$. We found no association between neck circumference and CAC using different cut-off points ( $p>0.05$ for all).

Conclusion: Neck circumference was significantly and independently associated with cc-IMT but not with CAC in women and men, indicating a possible effect of perivascular fat tissue on atherosclerosis.

(c) 2016 The Italian Society of Diabetology, the Italian Society for the Study of Atherosclerosis, the Italian Society of Human Nutrition, and the Department of Clinical Medicine and Surgery, Federico II University. Published by Elsevier B.V. All rights reserved.
\end{abstract}

\footnotetext{
* Corresponding author. Center for Clinical and Epidemiological Research, Hospital Universitário, Av. Lineu Prestes $25653^{\circ}$ andar, CEP 05508-000, São Paulo, SP, Brazil. Tel./fax: +55 1130919300.
}

\section{Introduction}

Obesity is a global epidemic of our time with increased mortality and morbidity [1]. Despite its tight connection with other cardiovascular risk factors and metabolic syndrome, it is now clear that different patterns of fat distribution confer heterogeneous additional cardiovascular risk beyond body-mass index (BMI) itself [2-5]. Body fat 
distribution is a matter of interest for more than 50 years now $[6,7]$, yet only recently the study of specific fat depots effects on cardiovascular risk has gained attention [8-11]. Neck circumference can be described as a marker of upper body subcutaneous fat deposit, which has been independently associated with several cardiometabolic risk factors such as total cholesterol [9,10], HDL-cholesterol [9,10], LDL-cholesterol $[8,10]$, triglycerides $[8,10,11]$, systolic and diastolic blood pressure levels [8-10] and fasting glucose $[8,10]$. These associations were reported in observational studies of diverse populations as significant even after multivariate adjustment including BMI and waist circumference. Changes in neck circumference were also correlated with changes in cardiovascular risk profile [12]. Some studies have also associated neck circumference with measures of metabolic syndrome and insulin resistance, as well $[4,8,13]$.

Common carotid intima-media thickness (cc-IMT) is a noninvasive measure that has been used as a surrogate outcome for atherosclerotic disease [14] in populationbased [15]and clinical studies [16]. More recently, it has been proposed as a potential predictor of individual cardiovascular risk in clinical practice [17]. As another noninvasive measure of subclinical atherosclerosis, coronary artery calcification (CAC) have also been used for risk prediction of cardiovascular events. The presence and extent of CAC is a well-known predictor of future risk for cardiovascular disease (CVD) and also for all-cause mortality in individuals with no previous history of CVD $[18,19]$.

The association between neck circumference and both these measurements of subclinical atherosclerosis has been studied in the Framingham Heart Study offspring, where the neck circumference was correlated to internal carotid intima-media thickness (IMT), a marker of subclinical atherosclerosis. In multivariable models, a $1-\mathrm{SD}$ increase in neck circumference was associated with a $0.071 \mathrm{~mm}$ increase in internal carotid IMT and with a $0.025 \mathrm{~mm}$ increase in common carotid IMT. Both associations remained significant after multivariable adjustment including BMI [20]. Pokharel et al., evaluated crosssectionally the relationship between neck circumference and subclinical atherosclerosis measured by CAC and carotid plaques in a middle-aged population of retired national football league players. Although they found a high prevalence of CAC and carotid plaques, they did not find any association of these subclinical atherosclerosis indexes with neck circumference [21].

The Brazilian Longitudinal Study of Adult Health (ELSABrasil) is an ongoing prospective cohort study of civil servants with relatively high prevalence of overweight and obesity. Thus, we decided to investigate neck circumference as a potential marker of subclinical atherosclerosis indexes through its association with both cc-IMT and CAC in the ELSA-Brasil São Paulo site.

\section{Methods}

ELSA-Brasil is a multicenter prospective cohort, which enrolled 15,105 civil servants aged 35-74 years (54\% women) from 6 Brazilian cities (Belo Horizonte, Porto Alegre, Rio de Janeiro, Salvador, São Paulo and Vitória [22-24]). The study aims to investigate factors associated with the development and progression of CVD, diabetes, and other chronic conditions. Baseline assessment consisted of an evaluation lasting approximately $7 \mathrm{~h}$, which included in-person interviews conducted by trained personnel [25]. These standardized interviews were focused on sociodemographic characteristics, health, and medical history, use of medication, as well as, clinical and laboratory measurements [26]. Approvals were obtained from the institutional review boards of all the centers, and all the subjects signed an informed consent form.

\section{Design and population study}

Of the 15,105 participants in ELSA-Brasil, CAC was done in a subsample of 4412 at the research center of Sao Paulo. We included in this analysis all individuals with complete data on cc-IMT, CAC and neck circumference measurement at baseline. We excluded 260 participants with known previous CVD (coronary heart disease, myocardial revascularization, heart failure and stroke), leaving 4152 participants that were included for this analysis.

\section{Common carotid intima-media thickness}

The technique for cc-IMT measurement has been previously applied in other population-based studies $[27,28]$, and it has been published in the ELSA-Brasil [29]. The protocol was performed using a Toshiba (Aplio $\mathrm{XG}^{\mathrm{TM}}$ ) with a $7.5 \mathrm{MHz}$ linear transducer. IMT was measured in the outer wall of a pre-defined carotid segment of $1 \mathrm{~cm}$ in length from $1 \mathrm{~cm}$ below carotid bifurcation, during three cardiac cycles. The carotid images during three cardiac cycles were obtained and sent to the centralized reading center in São Paulo. We used MIA ${ }^{\text {TM }}$ software to standardize the reading and interpretation of carotid scans as previously described. IMT measurements are presented as the maximum values for the thickness of the right and left arteries measured at the far wall.

\section{Coronary artery calcium score}

All participants underwent a CAC examination performed with a 64-detector computed tomography scanner (Brilliance 64, Philips Healthcare, Best, Netherlands). After the scout images, each patient underwent an ECG-gated prospective calcium score examination with a tube potential of $120 \mathrm{kV}$ and a tube current adjusted to body habitus. Images were reconstructed in $2.5 \mathrm{~mm}$ slice thickness using standard filtered back projection. The CAC was expressed as Agatston units 20, and the percentile was evaluated in a blinded fashion by an experienced cardiologist using semiautomatic software (Calcium Scoring, Philips Workstation). CAC severity was further categorized as 0 or $>0$, $<100$ or $\geq 100$, and $<400$ or $\geq 400$. 


\section{Anthropometric variables}

Height and weight were measured using a standardized scale, and the body-mass index was calculated by dividing body weight with the squared height in meters $\left(\mathrm{kg} / \mathrm{m}^{2}\right)$. Waist circumference $(\mathrm{cm})$ was measured using standardized procedures and equipment. Neck circumference was measured with an inelastic tape $(\mathrm{mm})$ immediately above the cricoid cartilage and perpendicular to the long axis of the neck, with the participant in a sitting position. All measurements were performed by trained personnel.

\section{Laboratory measurements}

After overnight fasting (8-14 h) plasma sample was collected in all participants. Fasting glucose was determined enzymatically by the hexokinase method. Total cholesterol, high-density lipoprotein cholesterol (HDLcholesterol) and triglycerides were determined by the enzymatic colorimetric method. Low-density lipoprotein cholesterol (LDL-C) was calculated by the Friedwald's equation or directly when triglyceride levels were greater than $400 \mathrm{mg} / \mathrm{dL}$.

\section{Other explanatory variables}

We evaluated age, sex, education (elementary, highschool, and college), smoking status (never, former, and current), self-reported skin color (white, brown, black Asian and native), leisure-physical activity (light, moderate and intense) and regular alcohol consumption (never, former, and current).

Blood pressure was obtained in the sitting position after a minimum rest period of $5 \mathrm{~min}$. Three consecutive readings were obtained for each participant, with a one-minute interval between each one. The mean of the two last measurements was defined as the office blood pressure. Hypertension was defined as the use of medication to treat hypertension, a systolic blood pressure $\geq 140 \mathrm{mmHg}$ or diastolic blood pressure $\geq 90 \mathrm{mmHg}$. Diabetes was defined as the presence of one of the following: medical history of diabetes, use of medication to treat diabetes, fasting plasma glucose $\geq 126 \mathrm{mg} / \mathrm{dL}$, 2-h glucose post load test $\geq 200 \mathrm{mg} / \mathrm{dL}$ or $\mathrm{HbA} 1 \mathrm{C} \geq 6.5 \%$. Hypercholesterolemia was defined as presence of one of the following: medical history of dyslipidemia, use lipid-lowering agents or LDL-C $>130 \mathrm{mg} / \mathrm{dL}$.

\section{Statistical analysis}

Categorical variables were reported as absolute values and percentages, and continuous variables as means and standard deviations $( \pm \mathrm{SD})$ or median and interquartile range (IQR). As neck circumference and both subclinical atherosclerosis measures differ significantly between sexes, we chose to perform the analysis separately by sex. CAC and cc-IMT were analyzed as dependent variables in corresponding models. CAC scores were categorized to binary variables using different cut-offs ( 0 vs. $>0,<100$ vs. $\geq 100,<400$ vs. $\geq 400$ ). A similar procedure was performed for cc-IMT values, using two different cut-offs based on the sample distribution $(<75$ th vs. $\geq 75$ th percentile; $<90$ th vs. $\geq 90$ th percentile). Binary logistic models were built using CAC score and cc-IMT as dependent variables according to the diverse cut-off points described above. For these models, neck circumference values were standardized to mean "zero" and standard deviation of "one". Subsequent adjustments were made for traditional cardiovascular risk factors as age, race, education, smoking, hypertension, diabetes, high LDL-C, and use of lipidlowering agents. Further, we constructed regression models that included BMI, waist circumference, and both BMI and waist circumference individually. Finally, we ran a model including all those variables, BMI, waist circumference (including an interaction term of these two). The main analysis was run excluding participants with a positive previous history of cardiovascular disease. However, we also run a sensitivity analysis including those participants. We did not evaluate plaques as part of this analysis. We chose to dichotomize IMT above percentile 75 and percentile 90 because this strategy permits the use of logistic regression models both for IMT and CAC A two-tailed level of significance was set at $5 \%$. Analyzes were carried out using the SPSS 20.0 statistical package.

\section{Results}

Of the 4152 participants from ELSA-Brasil in Sao Paulo, 2266 were women $(50.6 \pm 8.4 \mathrm{yrs})$, and 1886 were men (50.7 $\pm 9.0 \mathrm{yrs})$. Main characteristics of our study population are shown in Table 1. Participants included in our study were mostly White, overweight, sedentary and never smokers. Mean neck circumference was $33.6 \pm 2.4 \mathrm{~cm}$ and $38.8 \pm 2.7 \mathrm{~cm}$ for women and men, respectively.

Table 2 shows crude and adjusted odds ratio (OR) of 1-SD neck circumference with subclinical atherosclerosis in logistic models. CAC was not associated with neck circumference in the adjusted models. When we compared participants above the 75th percentile for cc-IMT to those below that percentile, however, ORs for cc-IMT 75th (95\% CI) were 1.63 (1.39-1.90) for women and 1.54 (1.34-1.76) for men. The association of the cc-IMT 75th with neck circumference remained significant for women 1.71 (1.40; $2.08)$ and for men $1.83(1.54 ; 2.16)$ after multivariate adjustment for known traditional risk factors such as age, race, hypertension, diabetes, dyslipidemia, and smoking. The further adjustment only for BMI, only for waist circumference and for both BMI and waist circumference decreased the strength of the association for both men and women, but it remained significant. For the association between neck circumference and the cc-IMT 90th percentile the ORs remained significant for both sexes after multivariable adjustment for sociodemographic and cardiovascular risk factors for women. However, for men further adjustment for only BMI and WC or both decreased the strength minimally but did not change our findings [1.66 $(1.19 ; 2.32)]$ while for women the ORs remained 
Table 1 Main characteristics of studied population according to sex.

\begin{tabular}{|c|c|c|}
\hline & Men & Women \\
\hline & $(\mathrm{N}=1886)$ & $(\mathrm{N}=2266)$ \\
\hline Age, ${ }^{a}$ years & $50.7(9.0)$ & $50.6(8.4)$ \\
\hline \multicolumn{3}{|l|}{ Race (\%) } \\
\hline White & $1064(57.4)$ & 1359 (60.6) \\
\hline Brown & $459(24.7)$ & $429(19.1)$ \\
\hline Black & $247(13.3)$ & $317(14.1)$ \\
\hline Asian & $58(3.1)$ & $122(5.4) 123$ \\
\hline Native & $27(1.5)$ & $16(0.7) 16$ \\
\hline \multicolumn{3}{|l|}{ Education, years (\%) } \\
\hline Elementary & $367(19.5)$ & $226(10)$ \\
\hline High-school & $780(41.4)$ & $939(41.4)$ \\
\hline College & $739(39.2)$ & $1101(48.6) 1103$ \\
\hline \multicolumn{3}{|l|}{$\begin{array}{l}\text { Leisure-time physical } \\
\text { activity (\%) }\end{array}$} \\
\hline Light & $1355(74.7)$ & $1784(81.7)$ \\
\hline Moderate & $270(14.9)$ & $245(11.2)$ \\
\hline Vigorous & $190(10.5)$ & $154(7.1)$ \\
\hline \multicolumn{3}{|l|}{ Smoking habit } \\
\hline Never & $910(48.3)$ & $1320(58.3)$ \\
\hline Former & $661(35)$ & $602(26.6)$ \\
\hline Current & 315 (16.7) & $344(15.2)$ \\
\hline \multicolumn{3}{|l|}{ Regular alcohol intake } \\
\hline Never & $96(5.1)$ & $393(17.3)$ \\
\hline Former & $387(20.5)$ & $423(18.7)$ \\
\hline Current & $1403(74.5)$ & $1450(64)$ \\
\hline Hypertension (\%) & $642(34.1))$ & $567(25)$ \\
\hline Diabetes mellitus (\%) & $424(22.5)$ & $364(16.1)$ \\
\hline LDL-cholesterol $\geq 130 \mathrm{mg} / \mathrm{dL}$ & $961(51)$ & $1063(46.9)$ \\
\hline Use of lipid-lowering agents & $201(10.7)$ & $261(11.5)$ \\
\hline $\mathrm{BMI}^{\mathrm{a}}\left(\mathrm{kg} / \mathrm{m}^{2}\right)$ & $27.1(4.4)$ & $27.3(5.1)$ \\
\hline 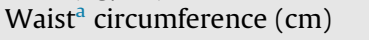 & $93.6(11.6)$ & $86.4(12.2)$ \\
\hline Neck circumference $^{\mathrm{a}}(\mathrm{cm})$ & $38.8(2.7)$ & $33.6(2.4)$ \\
\hline cc-IMT $\geq 75$ th percentile & $531(28.2)$ & $422(18.6)$ \\
\hline cc-IMT $\geq$ 90th percentile & $228(12.1)$ & $142(6.3)$ \\
\hline \multicolumn{3}{|l|}{ CAC (Agatston units) ${ }^{b}$} \\
\hline CAC (\%) & $0(0-26.8)$ & $0(0-0)$ \\
\hline 0 & $1155(61.2)$ & $1849(81.6)$ \\
\hline $1-99(\%)$ & $453(24)$ & $315(13.9)$ \\
\hline 100-399 (\%) & $177(9.4)$ & $80(3.5)$ \\
\hline$\geq 400(\%)$ & $101(5.4)$ & $22(1.0)$ \\
\hline
\end{tabular}

significant only prior to the adjustment for BMI or waist circumference.

Additionally, we repeated the same analysis including all individuals with previous cardiovascular disease as part of the sample. The results did not materially change (Supplementary Table 3).

\section{Discussion}

Neck circumference was significantly associated with ccIMT for both sexes in this subpopulation from ELSA-Brasil, but not with CAC. Compared to previous reports of Brazilian data, average $\mathrm{NC}$ was exactly the same as observed in a previous study for men; but for women, ELSA-Brasil values were lower $(33.6 \mathrm{~cm}$ in ELSA-Brasil vs. $35.9 \mathrm{~cm}$ in previous data) [27]. Our results for cc-IMT were similar to previous data from the Framingham Heart Study. They found a significant association between neck circumference and c-IMT even after adjustment for age, sex, systolic blood pressure, hypertension treatment, diabetes, total cholesterol-to-HDL-C ratio, smoking and BMI in 3274 participants. Interestingly, other adiposity measures as body-mass index and waist circumference showed that the associations with c-IMT were attenuated in both magnitude and significance after additional adjustment for NC [20]. Our current results for cc-IMT extend these findings to a larger sample from a geographically different population. However, further comparisons with our results are hampered by different statistical analysis strategy between studies. The Framingham Heart Study used linear regression models to investigate the association between adiposity measurements and cc-IMT. Because CAC scores have a zero-inflated distribution, the use of CAC scores as the dependent variable without a proper transformation in linear regression models would violate model assumptions. To avoid potential bias due to such a violation, we categorized both cc-IMT values and CAC scores and used logistic regression to assess associations and to enhance comparability across different outcome measures.

In a retrospective study of 522 retired NFL players (mean age 54 years) [21], Pokharel and colleagues reported no significant association between CAC and neck circumference after multivariable adjustment for age, race, systolic blood pressure, and high-sensitivity C-reactive protein [OR for $1-\mathrm{SD}$ increase in NC is 1.11 (95\% CI, 0.94-1.31)]. Except for the similar mean age, our study population included both sexes regardless of physical activity profile. Therefore, we wish to note that caution must be exercised in comparing these two studies, as neck circumference in retired National Football players may be relatively less reflective of regional adiposity compared to a sample of non-athletes of both sexes. Although, mean values of neck circumference in football league players were higher than in men of ELSA-Brasil $(43.2 \mathrm{~cm}$ in NFL players vs. 38.9 in ELSA-Brasil men), it is probable that neck circumference in NFL athletes might have a higher percentage of lean mass compared to the neck circumference from ELSA-Brasil participants. We were not able to find any other study that compared neck circumference with CAC.

It is very likely that CAC and cc-IMT measure different phenomena in the same way that the relationship between cIMT and carotid plaques [28-30]. A high cc-IMT could reflect not only a pathologic intimal thickening that is the first step of atherosclerosis process but also the hypertrophy of the media layer [14]. These differences may explain, at least partially, the heterogeneous association between neck circumference and both surrogates of the atherosclerotic disease described in this study. Unfortunately at this moment in our study we do not have a measure of discrete plaques in the carotid or coronary arteries. However, Pokharel et al. did not find any association between NC and CAC results similar to ours. In their study, carotid plaques were not associated with neck circumference either [21]. 
Table 2 Odds ratio (OR) and 95\% Confidence Interval (95\% CI) for the association between one standard deviation in neck circumference and the markers of subclinical atherosclerosis, stratified by sex.

\begin{tabular}{|c|c|c|c|c|c|}
\hline & $\mathrm{CAC}>0$ & $\mathrm{CAC} \geq 100$ & $\mathrm{CAC} \geq 400$ & cc-IMT > 75th percentile & cc-IMT > 90th percentile \\
\hline \multicolumn{6}{|l|}{ Women } \\
\hline Crude & $1.13(0.97 ; 1.33)$ & $1.14(0.85 ; 1.52)$ & $1.47(0.82 ; 2.65)$ & $1.63(1.39 ; 1.90)$ & $1.52(1.20 ; 1.94)$ \\
\hline Age-adjusted & $1.19(0.99 ; 1.43)$ & $1.17(0.86 ; 1.61)$ & $1.56(0.83 ; 2.94)$ & $1.92(1.60 ; 2.29)$ & $1.67(1.28 ; 2.18)$ \\
\hline Model 1 & $1.21(1.01 ; 1.47)$ & $1.24(0.89 ; 1.72)$ & $1.47(076 ; 2.86)$ & $1.89(1.57 ; 2.29)$ & $1.52(1.15 ; 2.01)$ \\
\hline Model 2 & $1.07(0.87 ; 1.31)$ & $1.10(0.73 ; 1.55)$ & $1.27(0.61 ; 2.64)$ & $1.71(1.40 ; 2.08)$ & $1.23(0.91 ; 1.66)$ \\
\hline Model 2 + BMI & $1.06(0.81 ; 1.38)$ & $1.31(0.83 ; 2.09)$ & $0.99(0.38 ; 2.62)$ & $1.49(1.15 ; 1.94)$ & $1.34(0.91 ; 1.98)$ \\
\hline Model 2 + WC & $0.96(0.73 ; 1.23)$ & $1.19(0.74 ; 1.92)$ & $0.84(0.31 ; 2.23)$ & $1.58(1.21 ; 2.06)$ & $1.14(0.76 ; 1.71)$ \\
\hline Model $2+$ BMI + WC & $0.99(0.75 ; 1.30)$ & $1.26(0.77 ; 2.05)$ & $0.86(0.32 ; 2.35)$ & $1.52(1.16 ; 1.99)$ & $1.21(0.80 ; 1.82)$ \\
\hline \multicolumn{6}{|l|}{ Men } \\
\hline Crude & $1.08(0.95 ; 1.22)$ & $0.98(0.82 ; 1.16)$ & $1.03(0.79 ; 1.35)$ & $1.54(1.34 ; 1.76)$ & $1.49(1.24 ; 1.78)$ \\
\hline Age-adjusted & $1.21(1.05 ; 1.39)$ & $1.10(0.91 ; 1.34)$ & $1.23(0.91 ; 1.64)$ & $1.90(1.60 ; 2.22)$ & $1.77(1.46 ; 2.16)$ \\
\hline Model 1 & $1.22(1.05 ; 1.41)$ & $1.09(0.89 ; 1.34)$ & $1.21(0.88 ; 1.66)$ & $1.99(1.69 ; 2.34)$ & $1.85(1.50 ; 2.28)$ \\
\hline Model 2 & $1.10(0.94 ; 1.29)$ & $0.93(0.75 ; 1.15)$ & $1.05(0.76-1.47)$ & $1.83(1.54 ; 2.17)$ & $1.75(1.40 ; 2.19)$ \\
\hline Model $2+$ BMI & $0.92(0.73 ; 1.15)$ & $0.75(0.55 ; 1.01)$ & $1.03(0.64 ; 165)$ & $1.66(1.29 ; 2.13)$ & $1.62(1.18 ; 2.25)$ \\
\hline Model 2 + WC & $0.95(0.76 ; 1.19)$ & $0.68(0.51 ; 0.92)$ & $0.99(0.62 ; 1.58)$ & $1.58(1.21 ; 2.06)$ & $1.73(1.26 ; 2.38)$ \\
\hline Model $2+$ BMI + WC & $0.90(0.72 ; 1.14)$ & $0.68(0.50 ; 0.94)$ & $0.99(0.61 ; 1.64)$ & $1.66(1.28 ; 2.14)$ & $1.66(1.19 ; 2.32)$ \\
\hline
\end{tabular}

In the Framingham Heart Study, Kathiresan et al. tried to establish the inter-relation across subclinical atherosclerosis measurements detected by three different imaging techniques. They assessed abdominal and thoracic aortic plaques using cardiovascular magnetic resonance, CAC and thoracic aortic calcification by electron beam computed tomography and cc-IMT by ultrasound in 292 participants with no previous cardiovascular disease [31]. They found a significant, positive, but weak correlation between CAC and cc-IMT. Also, they identified participants having a high atherosclerosis level for each test if the value was in the top $20 \%$ of the sex-specific distribution. For men and women, both CAC and c-IMT identified 30 participants with high atherosclerosis but only 13 participants were classified at high atherosclerosis level by both methods [31]. Another possibility to explain the positive association between neck circumference with cIMT could be a local effect of perivascular fat depots in the neck. Some authors classify fat in the neck as an ectopic fat depot with systemic action [32] while perivascular fat is associated only with local effects [33,34]. We can speculate that local effect of perivascular fat in the neck could explain the association between neck circumference and c-IMT in our results. Few studies have addressed fat depots with local action, and most of them studied epicardial fat tissue. The results showed a positive association between epicardial fat tissue and CAC $[35,36]$ and noncalcified plaques [37]. Recently a new index was proposed, the extra-media thickness (EMT), that included the jugular venous wall, interstitial tissue, perivascular fat, carotid artery adventitia and partly of the carotid artery media [38]. After the major cause of venous wall thickening, venous hypertension was excluded from the study, main determinants of EMT were arterial adventitia and perivascular fat as showed by Falk et al. [39]. Compared to IMT, EMT presented higher associations with obesityrelated measures. That EMT and IMT were significantly associated suggests that these indexes may have some common risk factors. Importantly, EMT could estimate the perivascular adipose tissue that produces several adipokines and cytokines. Dysfunctional perivascular adipose tissue may induce smooth muscle proliferation and vascular remodeling, and we may hypothesize that this could be measured as a high IMT. This phenomenon could also explain our positive results in the association of neck circumference and IMT. Beyond that, two main types of fat were found in human body. White adipose tissue is responsible for the storage of excessive energy as triglycerides while brown adipose tissue (BAT) is responsible for thermogenic energy dissipation. BAT depots have been found in cervical and mediastinal regions [40]. However, any positive effect of the presence of brown fat in the neck may be probably surpassed by the local effect of dysfunctional perivascular adipose which probably did not occur in mediastinal brown fat depots.

Limitations of this study encompass the cross-sectional nature of its design, which prevents further conclusions in terms of the direction of the association. Another limitation is the use of neck circumference as a surrogate for neck adiposity. Other methods, such as a CT-scan, could provide more valuable information on fat deposit in the neck of distinguishing the deep fat from subcutaneous fat. A third limitation is that we have no measures of carotid plaques or coronary obstruction. Although it is possible to obtain these measurements in the future, they are not available now. Finally we did not perform a complete reproducibility study for IMT measurements in ELSABrasil. However, other researchers have published the 
excellent reproducibility and variability of carotid structural parameters assessed with transcutaneous ultrasound $[41,42]$ and we followed a strict protocol, with centralized reading and a computerized edge-tracking multiframe image processing method to ensure correct IMT measurements in our study. We also did not perform a reproducibility study for CAC. As studies with multidetector tomography already had shown a high agreement, we preferred to not duplicate scans and their associated radiation exposure for methodological reasons. This strategy has also been chosen in other large cohorts as the German Heinz Nixdorf Recall study [43]. As a strength, we analyzed a well-defined population with two measurements of subclinical atherosclerosis using different cut-offs. To the best of our knowledge, this is the first study to compare neck circumference to cc-IMT and CAC in the same participants. We believe our findings have important clinical implications given that neck circumference could be used as a simple and inexpensive tool to identify individuals at high cardiovascular risk. This is of particular importance at early clinical stages of cardiovascular diseases. Future studies should focus on neck circumference's ability to predict cardiovascular events beyond other well established anthropometric measurements as BMI and waist circumference.

In conclusion, neck circumference was significantly associated with cc-IMT, but not with CAC in both sexes. These findings are hypothesis generating, and further research is needed to support the role for neck circumference as a marker of local atherosclerosis.

\section{Funding}

The ELSA-Brasil baseline study was supported by the Brazilian Ministry of Health (Science and Technology Department) and the Brazilian Ministry of Science and Technology and CNPq - National Research Council (grants \# 01060010.00 RS, 01060212.00 BA, 01060300.00 ES, 01 06 0278.00 MG, 01060115.00 SP, 01060071.00 RJ).

\section{Conflict of interest}

The authors declare no conflict of interest.

No part of this manuscript is under consideration for publication elsewhere.

\section{Acknowledgments}

The authors would also like to acknowledge the participation of the 15,105 individuals recruited for this study, without whom this study, and those based on the ELSABrasil cohort, would not have been possible.

\section{Appendix A. Supplementary data}

Supplementary data related to this article can be found at http://dx.doi.org/10.1016/j.numecd.2016.01.004.

\section{References}

[1] Vos T, Barber RM, Bell B, Bertozzi-Villa A, Biryukov S, Bolliger I, et al. Global, regional, and national incidence, prevalence, and years lived with disability for 301 acute and chronic diseases and injuries in 188 countries, 1990-2013: a systematic analysis for the Global Burden of Disease Study 2013. Lancet 2015;386:743-800.

[2] Canoy D, Boekholdt SM, Wareham N, Luben R, Welch A Bingham S, et al. Body fat distribution and risk of coronary heart disease in men and women in the European Prospective Investigation into Cancer and Nutrition in Norfolk cohort: a populationbased prospective study. Circulation 2007;116:2933-43.

[3] Fox CS, Massaro JM, Hoffmann U, Pou KM, Maurovich-Horvat P, Liu C-Y, et al. Abdominal visceral and subcutaneous adipose tissue compartments association with metabolic risk factors in the Framingham Heart Study. Circulation 2007;116:39-48.

[4] Yang GR, Yuan SY, Fu HJ, Wan G, Zhu LX, Bu XL, et al. Neck circumference positively related with central obesity, overweight, and metabolic syndrome in Chinese subjects with type 2 diabetes: Beijing Community Diabetes Study 4. Diabetes Care 2010;33: 2465-7.

[5] Schouten F, Twisk JW, de Boer MR, Stehouwer CD, Serné EH, Smulders YM, et al. Increases in central fat mass and decreases in peripheral fat mass are associated with accelerated arterial stiffening in healthy adults: the Amsterdam Growth and Health Longitudinal Study. Am J Clin Nutr 2011;94:40-8.

[6] Vague J. The degree of masculine differentiation of obesities a factor determining predisposition to diabetes, atherosclerosis, gout, and uric calculous disease. Am J Clin Nutr 1956;4:20-34.

[7] Freedman DS, Rimm AA. The relation of body fat distribution, as assessed by six girth measurements, to diabetes mellitus in women. Am J Public Health 1989;79:715-20.

[8] Preis SR, Massaro JM, Hoffmann U, D’Agostino Sr RB, Levy D, Robins SJ, et al. Neck circumference as a novel measure of cardiometabolic risk: the Framingham heart study. J Clin Endocrinol Metab 2010;95:3701-10.

[9] Liang J, Teng F, Liu X, Zou C, Wang Y, Dou L, et al. Synergistic effects of neck circumference and metabolic risk factors on insulin resistance: the Cardiometabolic Risk in Chinese (CRC) study. Diabetol Metab Syndr 2014;6:1-5.

[10] Zhou JY, Ge H, Zhu MF, Wang LJ, Chen L, Tan YZ, et al. Neck circumference as an independent predictive contributor to cardiometabolic syndrome. Cardiovasc Diabetol 2013;12:76.

[11] Arnold TJ, Schweitzer A, Hoffman HJ, Onyewu C, Hurtado ME, Hoffman EP, et al. Neck and waist circumference biomarkers of cardiovascular risk in a cohort of predominantly African-American college students: a preliminary study. J Acad Nutr Diet 2014;114: 107-16.

[12] Ben-Noun LL, Laor A. Relationship between changes in neck circumference and cardiovascular risk factors. Exp Clin Cardiol 2006; $11: 14$

[13] Laakso M, Matilainen V, Keinanen-Kiukaanniemi S. Association of neck circumference with insulin resistance-related factors. Int J Obes Relat Metab Disord 2002;26:873-5.

[14] Touboul P-J, Hennerici M, Meairs S, Adams H, Amarenco P, Bornstein N, et al. Mannheim carotid intima-media thickness consensus. Cerebrovasc Dis 2004-2006;2007(23):75-80.

[15] Heiss G, Sharrett AR, Barnes R, Chambless L, Szklo M, Alzola C. Carotid atherosclerosis measured by B-mode ultrasound in populations: associations with cardiovascular risk factors in the ARIC study. Am J Epidemiol 1991;134:250-6.

[16] Zanchetti A, Bond MG, Hennig M, Neiss A, Mancia G, Dal Palù C et al. Calcium antagonist lacidipine slows down progression of asymptomatic carotid atherosclerosis principal results of the European Lacidipine Study on Atherosclerosis (ELSA), a randomized, double-blind, long-term trial. Circulation 2002;106:2422-7.

[17] Lorenz MW, Markus HS, Bots ML, Rosvall M, Sitzer M. Prediction of clinical cardiovascular events with carotid intima-media thickness a systematic review and meta-analysis. Circulation 2007;115:459-67.

[18] Tota-Maharaj R, Blaha MJ, Blankstein R, Silverman MG, Eng J, Shaw LJ, et al. Association of coronary artery calcium and coronary heart disease events in young and elderly participants in the multi-ethnic study of atherosclerosis: a secondary analysis of a prospective, population-based cohort Mayo Clinic Proceedings. Elsevier; 2014. p. 1350-9. 
[19] Gepner AD, Young R, Delaney JA, Tattersall MC, Blaha M], Post WS, et al. Comparison of coronary artery calcium presence, carotid plaque presence, and carotid intima-media thickness for cardiovascular disease prediction in the multi-ethnic study of atherosclerosis. Circ Cardiovasc Imag 2015;8:e002262.

[20] Rosenquist KJ, Massaro JM, Pencina KM, D’Agostino RB, Beiser A, O'Connor GT, et al. Neck circumference, carotid wall intimamedia thickness, and incident stroke. Diabetes Care 2013;36: e153-4.

[21] Pokharel Y, Macedo FY, Nambi V, Martin SS, Nasir K, Wong ND, et al. Neck circumference is not associated with subclinical atherosclerosis in retired National Football League players. Clin Cardiol 2014;37:402-7.

[22] Aquino EM, Barreto SM, Bensenor IM, Carvalho MS, Chor D, Duncan BB, et al. Brazilian longitudinal study of adult health (ELSA-Brasil): objectives and design. Am J Epidemiol 2012;175: 315-24.

[23] Lotufo PA. Setting up the longitudinal study for adult health (ELSA-Brasil). Rev Saúde Pública 2013;47:3-9.

[24] Schmidt MI, Duncan BB, Mill JG, Lotufo PA, Chor D, Barreto SM, et al. Cohort profile: longitudinal study of adult health (ELSABrasil). Int J Epidemiol 2015 Feb;44(1):68-75. http://dx.doi.org/10.1093/ije/dyu027. Epub 2014 Feb 27.

[25] Bensenor IM, Griep RH, Pinto KA, CPd Faria, Felisbino-Mendes M, Caetano EI, et al. Routines of organization of clinical tests and interviews in the ELSA-Brasil investigation center. Rev Saúde Pública 2013;47:37-47.

[26] Chor D, de Mello Alves MG, Giatti L, Cade NV, Nunes MA, MdCB Molina, et al. Questionário do ELSA-Brasil: desafios na elaboração de instrumento multidimensional. Rev Saúde Pública 2013;47:27-36.

[27] Stabe C, Vasques AC, Lima MM, Tambascia MA, Pareja JC, Yamanaka A, et al. Neck circumference as a simple tool for identifying the metabolic syndrome and insulin resistance: results from the Brazilian Metabolic Syndrome Study. Clin Endocrinol (Oxf) 2013;78:874-81.

[28] Rundek T, Gardener H, Della-Morte D, Dong C, Cabral D, Tiozzo E, et al. The relationship between carotid intima-media thickness and carotid plaque in the Northern Manhattan Study. Atherosclerosis 2015;241:364-70.

[29] Santos IS, Bittencourt MS, Oliveira IR, Souza AG, Meireles DP, Rundek T, et al. Carotid intima-media thickness value distributions in the Brazilian Longitudinal Study of Adult Health (ELSA-Brasil). Atherosclerosis 2014;237:227-35.

[30] Santos IS, Alencar AP, Rundek T, Goulart AC, Barreto SM, Pereira AC, et al. Low impact of traditional risk factors on carotid intima-media thickness the ELSA-Brasil cohort. Arterioscl Thromb Vasc Biol 2015;35:2054-9.
[31] Kathiresan S, Larson MG, Keyes MJ, Polak JF, Wolf PA, D'Agostino RB, et al. Assessment by cardiovascular magnetic resonance, electron beam computed tomography, and carotid ultrasonography of the distribution of subclinical atherosclerosis across Framingham risk strata. Am J Cardiol 2007;99:310-4.

[32] Lim S, Meigs JB. Links between ectopic fat and vascular disease in humans. Arterioscler Thromb Vasc Biol 2014;34:1820-6.

[33] Britton KA, Fox CS. Ectopic fat depots and cardiovascular disease. Circulation 2011;124:e837-41.

[34] Lim S, Meigs JB. Ectopic fat and cardiometabolic and vascular risk. Int J Cardiol 2013;169:166-76.

[35] Kim BJ, Kim BS, Kang JH. Echocardiographic epicardial fat thickness is associated with coronary artery calcification - results from the CAESAR study. Circ J 2015;79:818-24.

[36] Ahmadi N, Nabavi V, Yang E, Hajsadeghi F, Lakis M, Flores F, et al. Increased epicardial, pericardial, and subcutaneous adipose tissue is associated with the presence and severity of coronary artery calcium. Acad Radiol 2010;17:1518-24.

[37] Alexopoulos N, McLean DS, Janik M, Arepalli CD, Stillman AE, Raggi P. Epicardial adipose tissue and coronary artery plaque characteristics. Atherosclerosis 2010;210:150-4.

[38] Haberka M, Sosnowski M, Zuziak-Pruska J, Gąsior Z. Extra-media thickness and epicardial fat: comparison of a novel carotid artery ultrasound index and a well-established cardiac magnetic resonance fat quantification method. Nutr Metab Cardiovasc Dis 2015 Aug;25(8):763-70. http://dx.doi.org/10.1016/j.numecd.2015. 04.011.

[39] Falk E, Thim T, Kristensen IB. Atherosclerotic plaque, adventitia, perivascular fat, and carotid imaging. JACC Cardiovasc Imaging 2009;2:183-6.

[40] Kolonin MG. How brown is brown fat that we can see? Adipocyte 2014;3:155-9.

[41] Lundby-Christensen L, Almdal TP, Carstensen B, Tarnow L, Wiinberg N. Carotid intima-media thickness in individuals with and without type 2 diabetes: a reproducibility study. Cardiovasc Diabetol 2010;9:40.

[42] Caviezel S, Dratva J, Schaffner E, Teynor A, Baumstark MW, Schindler C, et al. Variability and reproducibility of carotid structural and functional parameters assessed with transcutaneous ultrasound - results from the SAPALDIA cohort study. Atherosclerosis 2013;231:448-55.

[43] Schmermund A, Möhlenkamp S, Stang A, Grönemeyer D, Seibel R, Hirche $\mathrm{H}$, et al. Assessment of clinically silent atherosclerotic disease and established and novel risk factors for predicting myocardial infarction and cardiac death in healthy middle-aged subjects: rationale and design of the Heinz Nixdorf RECALL study. Am Heart J 2002;144:212-8. 